\title{
Prospective Effects of Manual Diaphragmatic Release and Thoracic Lymphatic Pumping in Childhood Asthma
}

\author{
Ragab K Elnaggar, Mohammed A Shendy, and Mostafa Z Mahmoud
}

\begin{abstract}
BACKGROUND: Manual noninvasive respiratory techniques have traditionally been used to treat respiratory pathologies. The aim of this study was to analyze the effects of the diaphragmatic release technique and the thoracic lymphatic pump technique versus conventional respiratory retraining in children with asthma. METHODS: Using a quasi-experimental design, 60 children with asthma were allocated to undergo the diaphragmatic release technique $(n=20)$, thoracic lymphatic pump technique $(n=20)$, or conventional respiratory retraining $(n=20)$ in this study. Serum immunoglobulin $\mathbf{E}$ levels, diaphragmatic mobility, pulmonary function, and $\mathbf{P}_{(\mathrm{A}-\mathrm{a}) \mathrm{O}_{2}}$ were assessed before and after 12 treatment sessions that were conducted over nonconsecutive days in a 4-week program. RESULTS: After 12 treatments, the changes in the serum immunoglobulin E level for each group was not significantly different from the other groups. Compared with conventional respiratory retraining, the diaphragmatic release technique was associated with a significant improvement in $\mathrm{FVC}(P=.001)$ and $\mathrm{FEV}_{1}(P=.002)$; the thoracic lymphatic pump technique showed no differences. With regard to diaphragmatic mobility, both the diaphragmatic release technique and the thoracic lymphatic pump technique yielded significantly favorable effects when compared with conventional respiratory retraining $(P<.001$ and $P=.01$, respectively). Further, no significant between-group differences were detected in terms of the $\mathrm{P}_{(\mathrm{A}-\mathrm{a}) \mathrm{O}_{2}}(P=.07)$. CONCLUSIONS: The thoracic lymphatic pump technique and conventional respiratory retraining approaches were helpful interventions that could be used to alleviate the symptoms of childhood asthma. Nevertheless, the diaphragmatic release technique was a potentially more effective intervention. Key words: asthma; diaphragmatic release technique; thoracic lymphatic pump technique; conventional respiratory retraining. [Respir Care 2019;64(11):1422-1432. (C) 2019 Daedalus Enterprises]
\end{abstract}

\section{Introduction}

Asthma has been identified as one of the most prevalent chronic respiratory disorders to occur in children over the past few decades. It is a heterogeneous disease that presents in multiple ways and includes airway inflammation, bronchospasm, and airway obstruction. Asthma also fea-

Dr Elnaggar is affiliated with the Department of Physical Therapy for Pediatrics, Faculty of Physical Therapy, Cairo University, Cairo, Egypt, and with the Department of Physical Therapy and Health Rehabilitation, College of Applied Medical Sciences, Prince Sattam bin Abdulaziz University, Al-Kharj, Kingdom of Saudi Arabia. Dr Shendy is affiliated with the Department of Physical Therapy for Cardiovascular, Respiratory Disorders and Geriatrics, Faculty of Physical Therapy, Cairo University, Cairo, Egypt. Dr Mahmoud is affiliated with the Department of Radiology and Medical Imaging, College of Applied Medical Sciences, Prince Sattam bin Abdulaziz University, Al-Kharj, Kingdom of Saudi Arabia. tures associated clinical manifestations, such as eosinophil and mast cell infiltration. ${ }^{1}$ Like other allergic diseases, asthma is characterized by elevated levels of serum immunoglobulin (Ig) E, which interact with antigens and lead to a variety of immunologic sequelae. ${ }^{2}$ During an asthma exacerbation, the lungs and airways overreact to allergens and breathing becomes harder. ${ }^{3}$ At this time, the alveolararterial oxygen difference $\left(\mathrm{P}_{(\mathrm{A}-\mathrm{a}) \mathrm{O}_{2}}\right)$ rises, ${ }^{4}$ and the air is trapped in the non-dependent areas of the lung in moderate

\footnotetext{
The authors have disclosed no conflicts of interest.
}

Correspondence: Ragab K Elnaggar PhD, 7 Ahmed Elzayat Street Bein Elsarayat, PO 12624, Dokki, Giza, Egypt. E-mail: rke_pt2001@yahoo.com.

DOI: $10.4187 /$ respcare. 06716 
and severe cases.5,6 Airway obstruction, air trapping, and pulmonary hyperinflation may limit diaphragmatic movement, ${ }^{7,8}$ which is associated with pulmonary function impairment. 9

Several manual techniques have been shown to improve lung function, increase diaphragm and rib-cage mobility, and, possibly, enhance immune function in patients with respiratory diseases. ${ }^{10-14}$ The diaphragmatic release technique is a manual technique that was developed with the aim of indirectly elongating tight diaphragmatic muscle fibers while promoting greater and more efficient muscle contraction. ${ }^{15}$ The diaphragmatic release technique has been used in clinical practice as part of osteopathic medicine or manual therapy techniques to enhance pulmonary function and to improve thoracic mobility in both healthy individuals and patients with COPD or asthma, ${ }^{15-19}$ However, the scientific evidence about its effect is still insufficient, particularly in children with asthma. The thoracic lymphatic pump technique is another noninvasive and costeffective technique for children with asthma. ${ }^{20}$ In the thoracic lymphatic pump technique, a compressive force is applied to the thoracic cage during ventilation to create a difference between the intra-abdominal and intra-thoracic pressure. ${ }^{21}$ In addition to its advantageous effects on lymphatic and venous drainage, the thoracic lymphatic pump technique can enhance deep diaphragmatic breathing by controlling upper-chest movement. ${ }^{12}$ Nevertheless, the effect of the thoracic lymphatic pump technique in children with asthma remains uncertain.

Conventional respiratory retraining for patients with asthma involves a set of breathing and relaxation techniques that has been advocated for asthma control. These techniques include diaphragmatic breathing, nasal breathing, breathing control exercises, ${ }^{22,23}$ and a complementary progressive muscle relaxation technique. ${ }^{24}$ Although varying claims of efficacy have been made for each of the techniques described here, no specific technique has been endorsed by mainstream respiratory rehabilitation practice. Therefore, the present study was conducted to evaluate the effects of the diaphragmatic release technique and thoracic lymphatic pump technique in comparison with conventional respiratory retraining in children with asthma.

\section{Methods}

\section{Study Design}

A single-blind, quasi-randomized experimental study design was used at the laboratories of the College of Applied Medical Sciences, Prince Sattam bin Abdulaziz University (Kingdom of Saudi Arabia), and the laboratories of King Khalid Hospital in Al-Kharj, Kingdom of Saudi Arabia, from September 2017 to October 2018. The study protocol

\section{QUICK LOOK}

\section{Current knowledge}

Airflow limitation and pulmonary hyperinflation in asthma may give rise to shortening of the diaphragm and, thus, limit craniocaudal movement. Further, increased respiratory muscle loading and decreased diaphragmatic excursion change the total thoracic compliance and lower the capacity to achieve an effective respiratory cycle. A variety of manual therapy protocols that have the potential to improve pulmonary function are used in patients with pulmonary diseases. Nevertheless, no specific technique has been endorsed by standard pulmonary rehabilitation programs.

\section{What this paper contributes to our knowledge}

We analyzed the effect of the diaphragmatic release technique and the thoracic lymphatic pump technique compared to conventional respiratory retraining in children with asthma. Overall, the diaphragmatic release technique was more effective for demonstrating improvements in $\mathrm{FVC}, \mathrm{FEV}_{1}$, diaphragmatic mobility, and $\mathrm{P}_{(\mathrm{A}-\mathrm{a}) \mathrm{O}_{2}}$. However, both thoracic lymphatic pump technique and conventional respiratory retraining could be used to effectively reduce the symptoms of asthma in children.

was compliant with both institutional ethics principles and the Declaration of Helsinki. Before their involvement in the study, participating children's parents or guardians were asked to provide their informed consent.

The study population was selected via convenience sampling, and the sample size was determined based on a type- 1 error of $5 \%$ and a power of $80 \%$ as determined by estimates of the mean FVC values (Mean 1, 70.7; Mean 2, 73; Mean 3, 69.3) and the corresponding SD $\left(\mathrm{S}_{\text {pooled }}=3.7\right.$, if the $\mathrm{SD}$ within each group were equal to the pooled SD). These values were collected during a small pilot study. An overall sample size of 60 subjects was determined for this study based on these assumptions ( $n=20$ patients in each group). Any participants who withdrew from the study were compensated. The analysis was completed by using G*Power 3.0.10 (Neu-Isenburg, Germany)..$^{25}$

\section{Participants}

The participants were recruited from King Khalid Hospital and 2 other referral hospitals in Al-Kharj, Kingdom of Saudi Arabia, between September 2017 and October 2018. Details that pertain to the inclusion and exclusion 
criteria were thoroughly explained to the participants' parents and guardians at the time of recruitment, and they were reminded of these criteria $2-3 \mathrm{~d}$ before scheduling their participation date. The inclusion criteria were moderate (peak expiratory flow [PEF], 60-80\%) or severe asthma (PEF $<60 \%$ ), ${ }^{26}$ well-controlled asthma with no changes in asthma medication use for $\geq 1$ month; had taken stable doses of inhaled corticosteroids for at least 1 month before enrollment in the study; between the ages of 10 and $18 \mathrm{y}$; and a body mass index $<30 \mathrm{~kg} / \mathrm{m}^{2}$. The exclusion criteria included unstable asthma, exacerbation of asthma symptoms that required the use of systemic corticosteroids in the previous 4 week or during the study period, other respiratory or health-related problems that conferred greater morbidity than asthma, a history of thoracic surgery, and an inability to understand instructions necessary for assessment and treatment.

\section{Participants' Allocation}

A quasi-random allocation technique was used to assign the participants to 1 of the 3 treatment conditions. The participants were sequentially allocated into each condition based on the order in which they were recruited into the study. The participants were allocated to the diaphragmatic release technique group, thoracic lymphatic pump technique group, and conventional respiratory retraining group, in that order. Further, on the exclusion or withdrawal of a participant from any group, an alternate participant was recruited and allocated to that group.

\section{Outcome Measures}

The pulmonary function assessor and the radiologist who collected the data were blinded to the participants' group allocation. All the participants completed the same measurements before and immediately after the intervention (ie, after the 12th session). The outcome measures included serum IgE, diaphragmatic mobility, pulmonary function, and $\mathrm{P}_{(\mathrm{A}-\mathrm{a}) \mathrm{O}_{2}}$.

\section{Total Serum IgE}

Each participant was seated comfortably for $15 \mathrm{~min}$. Before blood sampling, the skin area over the median cubital vein or dorsal metacarpal veins was cleaned with $70 \%$ ethyl alcohol and was left to dry. A tourniquet was applied $7.5 \mathrm{~cm}$ above the puncture site.Vacutainers (Becton Dickinson, Plymouth, UK) then were used to collect $3 \mathrm{~mL}$ of blood. The blood sample was left undisturbed for 30 min until complete clotting. The serum was separated from the clot by centrifugation and then the serum was stored at $-20^{\circ} \mathrm{C}$ until the analysis was carried out. Total serum $\operatorname{IgE}$ were assessed at $450 \mathrm{~nm}$ by using enzyme- linked immunosorbent assay kits and the Organon Teknika Microwell system (Organon Teknika Corp, Boxtel, the Netherlands). Serum IgE were expressed as IU/mL. ${ }^{27}$

\section{Pulmonary Function Test}

FVC, $\mathrm{FEV}_{1}$, and PEF were measured for each participant by using a portable MicroLab spirometer (Vyaire Medical, Mettawa, Illinois) according to the current standards for lung function testing. ${ }^{28}$ An orientation session was provided to each participant, and the procedure was explained before the actual test was conducted. The participants were previously instructed to avoid strenuous activities and heavy meals before the test. Each participant assumed an upright standing position; then, a soft clip was applied to the nostrils to prevent air leakage from the nose. With the lips tightly closed on the mouthpiece, each patient was first instructed to breathe normally for several cycles. They were then asked to breathe in slowly and as deeply as possible, and then to breathe out forcefully. To ensure repeatability, 3 trials were performed, and the highest scores were further analyzed. The FVC, $\mathrm{FEV}_{1}$, and PEF were expressed as a percentage of the predicted values.

\section{Diaphragmatic Mobility}

A sonographic examination of diaphragmatic mobility was performed by using a high-resolution ultrasound scanner (Logiq 500, Pro Series, GE Medical Systems, Milwaukee, Wisconsin). The diaphragmatic movement was recorded in M-mode. To maintain a constant angle of incidence, simultaneous imaging in B-mode was provided (Fig. 1). Each participant was evaluated, while the participant was in the horizontal dorsal decubitus position, by using a $3.5 \mathrm{MHz}$ phased-array probe that was applied subcostally at the anterior axillary line. The probe was directed medially, cranially, and dorsally, and targeted the liver. Diaphragmatic mobility was identified by assessing the craniocaudal displacement of the liver during the maximum inspiratory and expiratory capacity, and it was demarcated by the cursor in millimeters. ${ }^{29}$ The test was repeated for each participant until 3 satisfactory trials were obtained, and the average value of the 3 trials served as the final value used for statistical analysis. All the participants were assessed by the same radiologist who was blinded to the treatment.

$\mathbf{P}_{(\mathrm{A}-\mathrm{a}) \mathbf{O}_{2}}$

A blood sample was drawn from either the radial or the brachial arteries after each participant was seated comfortably to allow for quiet breathing of the room air for $10 \mathrm{~min}$. $\mathrm{P}_{\mathrm{aO}_{2}}$ and $\mathrm{P}_{\mathrm{aCO}}$ were measured right after the sample was 


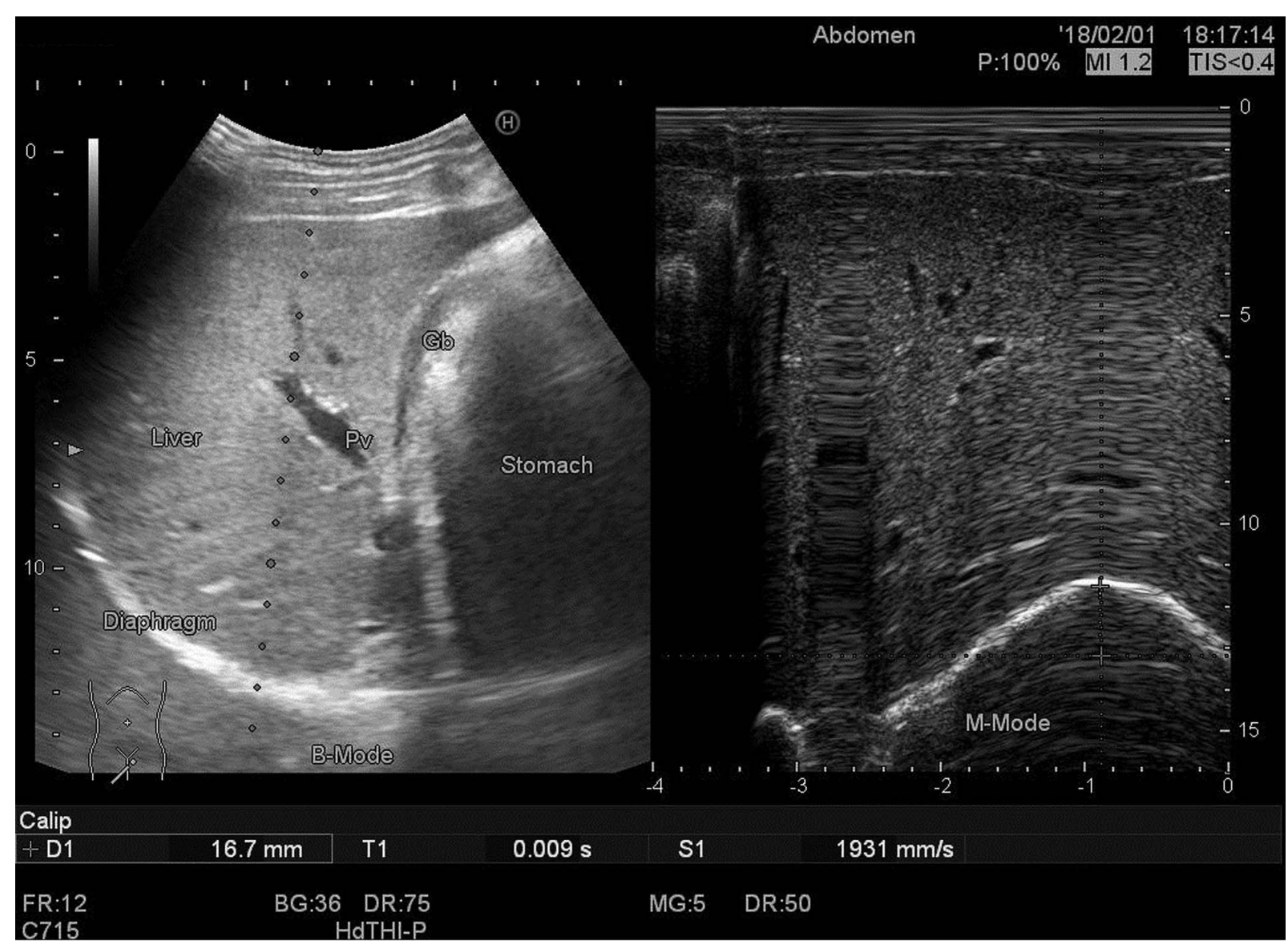

Fig. 1. Ultrasonography of the diaphragm.

obtained by using a Spectra metabolic cart (Sensor Medics, Yorba Linda, California). $\mathrm{P}_{(\mathrm{A}-\mathrm{a}) \mathrm{O}_{2}}$ was calculated from the following equation:

$$
\mathrm{P}_{(\mathrm{A}-\mathrm{a}) \mathrm{O}_{2}}=\mathrm{P}_{\mathrm{aO}_{2}}-\mathrm{P}_{\mathrm{aO}}
$$

where $\mathrm{P}_{\mathrm{aO}_{2}}$ is the partial alveolar oxygen pressure.

$\mathrm{P}_{\mathrm{aO}}$ was determined by the arterial blood gas analysis, and the $\mathrm{P}_{\mathrm{aO}}$ was calculated from the following equation:

$$
\mathrm{P}_{\mathrm{aO}_{2}}=\left(\mathrm{P}_{\mathrm{atm}}-\mathrm{P}_{\mathrm{water}}\right) \mathrm{F}_{\mathrm{IO}_{2}}-\mathrm{P}_{\mathrm{aCO}_{2}} / 0.8
$$

where $\mathrm{P}_{\mathrm{atm}}$ is the atmospheric pressure, $\mathrm{P}_{\mathrm{water}}$ is the vapor pressure of water at body temperature, $\mathrm{F}_{\mathrm{IO}_{2}}(21 \%$ of room air), and 0.8 is the respiratory quotient. ${ }^{30}$

\section{Intervention}

The participants in the 3 groups received a total of 12 treatments sessions (ie, 3 times a week over a 4-week period). The treatment was performed by 3 well-trained physical therapists (RKE, MAS) who were familiar with the study interventions. The participants in each group were treated by the same therapist to ensure consistent application of each treatment. The participants were assigned to the following treatments.

\section{Diaphragmatic Release Technique}

Treatment with the diaphragmatic release technique was directed to optimize the function of the diaphragm by means of stretching its fibers and releasing it from the surrounding tissues.

While the participant lay in the supine position and the therapist stood at the participant's head, the therapist passed his hands (the hypothenar and the lateral 3 fingers) underneath the costal cartilage of the seventh to the tenth ribs bilaterally, with the therapist's forearm aligned up toward the subject's shoulder. Then, the therapist quietly drew the ribs upward and slightly laterally during the inspiratory phase, in association with costal elevation. The therapist then went deeply with both hands toward the inner costal margin during the expiratory phase to resist the rebounding movement of the thoracic cage. The depth of this 
manual contact was progressively increased in subsequent respiratory cycles. The procedure was applied as demonstrated by Rocha et al, ${ }^{16}$ with minimum modification to ensure ease of application to the study population. The maneuver was repeated in 4 sets, each of which consisted of 5 deep breaths with 2-min intervals in between.

\section{Thoracic Lymphatic Pump Technique}

The thoracic lymphatic pump technique incorporates rhythmic chest-wall compression during the respiratory cycle, which is intended to trigger alveolar and airway expansion to enhance deep diaphragmatic breathing. The participant lay in the supine position; the therapist was positioned at the participant's head, facing the participant. The therapist then placed the thenar eminence of each hand to the pectoral region infraclavicularly and the other fingers were spread around the thoracic cage and angled toward the body's side to create a consistent, compressive force across the thoracic cage. The participant was then allowed to breathe in deeply and breathe out. While breathing out, rhythmic oscillatory compression in the posterior and caudal direction was applied to the chest wall. By the end of the expiratory phase, the compressive force was maintained, and the participant was asked to take another deep breath. In this way, the participant encountered some resistance equivalent to the chest-wall movement during inspiration. The maneuver was repeated for 5 respiratory cycles, then the therapist slowly reduced the compressive force and withdrew his hands to allow for full inspiration. ${ }^{13}$

\section{Conventional Respiratory Retraining}

A physical therapist-led respiratory retraining program for patients with asthma was individually administered with the aim of alleviating hyperventilation and hyperinflation, promoting normalization of the breathing pattern, and enhancing the strength of the respiratory muscles. This training process comprised the following steps:

1. Slow and deep diaphragmatic breathing

2. Nasal breathing with pursed lip expiration (the participants were instructed to focus on their expiratory pressure against pursed lips)

3. Breathing control and breathing-hold exercises (endinspiratory breathing hold to improve collateral ventilation and end-expiratory hold to correct hyperventilation)

4. Inspiratory muscle retraining (a pressure threshold loading protocol was implemented for 20 breaths)

5. Relaxation techniques: Each subject was taught to deliberately create tension in the abdominal, chest, neck, and shoulder-girdle muscles, and then to relax the mus- cles and focus his or her attention toward muscle relaxation as the tension loosened up.

\section{Statistical Analysis}

All data were checked for normality by using the Shapiro-Wilk test. Continuous data are presented as the mean \pm SD (95\% CI for the means). One-way analysis of variance was used to explore the differences between groups, and the post hoc Tukey-Kramer honest significant difference test was used for pairwise comparisons. Pairedsamples $t$ tests were used to calculate the pre- and posttreatment mean differences within each group. Cohen's d was used to estimate the effect sizes for the standardized differences in the paired-samples $t$ tests. Statistical significance was set at $P<.05$. The analysis was completed by using MedCalc software v15.8 (MedCalc Software, Mariakerke, Belgium).

\section{Results}

Eighty-three individuals were potentially eligible to take part in the study. Sixteen were initially excluded because they did not meet the inclusion criteria. Seven were excluded after enrollment because 4 of them missed 2 consecutive treatments and 3 of them had exacerbated symptoms that required medication changes; a total of 60 participants completed the study. The baseline demographic and clinical characteristics of the participants are presented in Table 1; the study groups were well balanced, except for body mass index.

\section{Serum IgE}

The serum IgE data of the study groups are presented in Table 2. The serum IgE values in all the groups were comparable before treatment $(P=.26)$. A statistically significant variation was seen among the study groups after treatment $(P=.046)$. The post hoc analysis showed that each group was not significantly different from the other groups. Within-group analysis showed a significant reduction in $\mathrm{IgE}$ for all the groups (diaphragmatic release technique, $P<.001$; thoracic lymphatic pump technique, $P=.032$; and conventional respiratory retraining, $P=$ $.033)$.

\section{Pulmonary Function}

As shown in Table 3, the pulmonary function values (FVC, $P=.09 ; \mathrm{FEV}_{1}, P=.41$; and PEF, $P=.78$ ) for all the groups were similar before treatment. Statistically significant between-groups differences were seen for FVC $(P=.001)$ and $\mathrm{FEV}_{1}(P=.003)$ after treatment, with no detectable differences in $\operatorname{PEF}(P=.14)$. With regard to the 
Table 1. Demographic Characteristics of Subjects at Baseline

\begin{tabular}{|c|c|c|c|c|}
\hline Characteristics & DRT Group & TLPT Group & CRR Group & $P$ \\
\hline Age, mean \pm SD y & $13.5 \pm 2.9$ & $14.6 \pm 2.5$ & $12.9 \pm 2.3$ & .12 \\
\hline Boys/girls, $n$ & $16 / 4$ & $14 / 6$ & $12 / 8$ & .39 \\
\hline Weight, mean \pm SD kg & $43.25 \pm 7.97$ & $46.95 \pm 7.83$ & $41.45 \pm 8.61$ & .10 \\
\hline Height, mean \pm SD m & $1.37 \pm 0.11$ & $1.43 \pm 0.09$ & $1.41 \pm 0.10$ & .16 \\
\hline $\mathrm{BMI}$, mean $\pm \mathrm{SD} \mathrm{kg} / \mathrm{m}^{2}$ & $22.95 \pm 2.42$ & $22.63 \pm 1.96$ & $20.74 \pm 2.06$ & .004 \\
\hline Severity, moderate/severe, $n$ & $13 / 7$ & $18 / 2$ & $15 / 5$ & .17 \\
\hline $\mathrm{FVC}$, mean $\pm \mathrm{SD}$ & $72.15 \pm 5.03$ & $73 \pm 2.92$ & $69.55 \pm 6.73$ & .09 \\
\hline $\begin{array}{l}\mathrm{DRT}=\text { diaphragmatic release technique } \\
\mathrm{TLPT}=\text { thoracic lymphatic pump techni } \\
\mathrm{CRR}=\text { conventional respiratory retrainin } \\
\mathrm{BMI}=\text { body mass index }\end{array}$ & & & & \\
\hline
\end{tabular}

Table 2. Immunoglobulin E in the Study Groups

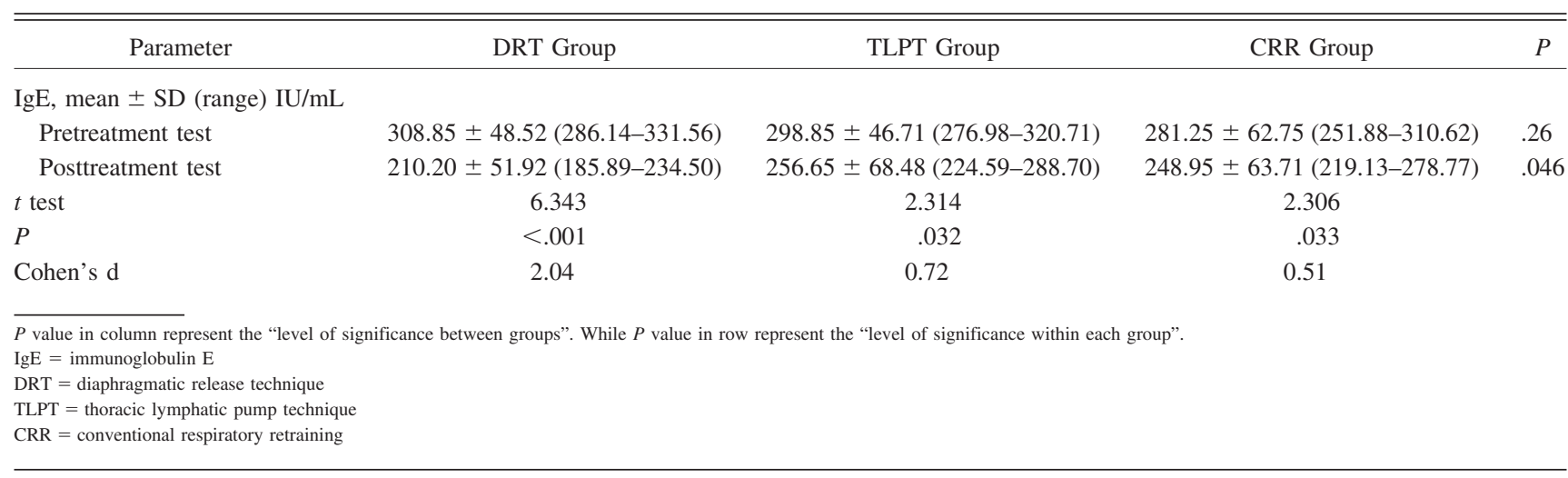

FVC, the pairwise comparisons showed a preferable effect of the diaphragmatic release technique when compared with conventional respiratory retraining $(P=.001)$ but not to the thoracic lymphatic pump technique $(P=.16)$. Further, both the thoracic lymphatic pump technique and the conventional respiratory retraining yielded a similar effect $(P=.11)$. With regard to $\mathrm{FEV}_{1}$, the diaphragmatic release technique produced a better effect than did the conventional respiratory retraining $(P=.002)$ but not better than the thoracic lymphatic pump technique $(P=.21)$, and the effect for both the thoracic lymphatic pump technique and the conventional respiratory retraining was similar $(P=.14)$. In addition, within-groups comparisons showed significant improvements across all pulmonary function measures for all groups with a medium $(0.5<$ Cohen's $\mathrm{d}<0.8$ ) to large (Cohen's $\mathrm{d}>0.8$ ) effect size.

\section{Diaphragmatic Mobility}

Changes in diaphragm mobility are shown in Table 4. No significant between-groups differences were detected before treatment $(P=.36)$. A significant difference was observed between the groups after treatment $(P<.001)$.
The post hoc analysis revealed a favorable effect of the diaphragmatic release technique $(P<.001)$ and the thoracic lymphatic pump technique $(P=.01)$ when compared with the conventional respiratory retraining, whereas the diaphragmatic release technique and thoracic lymphatic pump technique groups were not significantly different from each other $(P=.36)$. Furthermore, diaphragmatic displacement had significantly changed within all the groups, with a large effect found for the diaphragmatic release technique and the thoracic lymphatic pump technique (Cohen's $d>0.8$ ) and a medium effect for conventional respiratory retraining $(0.5<$ Cohen's $d<0.8)$.

$\mathbf{P}_{(\mathrm{A}-\mathbf{a}) \mathrm{O}_{2}}$

Changes in the $\mathrm{P}_{(\mathrm{A}-\mathrm{a}) \mathrm{O}_{2}}$ and blood gases are shown in Table 5. The study groups were similar $(P=.09)$ before treatment. No significant differences in the $\mathrm{P}_{(\mathrm{A}-\mathrm{a}) \mathrm{O}_{2}}$ and $\mathrm{P}_{\mathrm{aO}_{2}}$ were found among the study groups after treatment $(P=.07$ and $P=.31$, respectively $)$. Nevertheless, significant differences in $\mathrm{P}_{\mathrm{aO}_{2}}$ and $\mathrm{P}_{\mathrm{aCO}}$ were indicated between the study groups after treatment $(P=.035$ and $P=.037$, respectively). The post hoc analysis showed that $\mathrm{P}_{a O_{2}}$ was 
Manual Manipulation Techniques in Childhood Asthma

Table 3. Values of Pulmonary Function Measures Within and Between Groups

\begin{tabular}{|c|c|c|c|c|}
\hline Variable & DRT Group & TLPT Group & CRR Group & $P$ \\
\hline \multicolumn{5}{|l|}{ FVC } \\
\hline Pretreatment test, mean \pm SD (range) & $72.15 \pm 5.03(69.79-74.50)$ & $73 \pm 2.92(71.63-74.37)$ & $69.55 \pm 6.73(66.39-72.70)$ & .09 \\
\hline Posttreatment test, mean \pm SD (range) & $78.50 \pm 3.58(76.83-80.17)$ & $75.90 \pm 5.25(73.44-78.36)$ & $73.05 \pm 4.19(71.09-75)$ & .001 \\
\hline$P$ & $<.001$ & .032 & .048 & \\
\hline Change, $\%$ & 8.8 & 4 & 5 & \\
\hline Cohen's d & 1.45 & 0.68 & 0.62 & \\
\hline \multicolumn{5}{|l|}{$\mathrm{FEV}_{1}$} \\
\hline Pretreatment test, mean \pm SD (range) & $50.40 \pm 6.23(47.50-53.31)$ & $52.25 \pm 5.92(49.48-55.02)$ & $49.85 \pm 5.46(47.29-52.41)$ & .41 \\
\hline Posttreatment test, mean $\pm \mathrm{SD}$ (range) & $59.90 \pm 5.61(57.27-62.52)$ & $56.80 \pm 4.96(54.48-59.12)$ & $53.30 \pm 6.53(50.24-56.37)$ & .003 \\
\hline$P$ & .001 & .007 & .02 & \\
\hline Change $\%$ & 18.8 & 8.7 & 6.9 & \\
\hline Cohen's d & 1.60 & 0.83 & 0.57 & \\
\hline \multicolumn{5}{|l|}{ PEF } \\
\hline Pretreatment test, mean \pm SD (range) & $63.15 \pm 8.23(59.29-67)$ & $62.55 \pm 7.34(59.12-65.98)$ & $61.45 \pm 7.72(57.84-65.06)$ & .78 \\
\hline Posttreatment test, mean $\pm \mathrm{SD}$ (range) & $71.20 \pm 8.92(67.02-75.38)$ & $67.60 \pm 9.41(63.19-72)$ & $66 \pm 6.33(63.04-68.96)$ & .14 \\
\hline$P$ & .002 & .02 & .02 & \\
\hline Change, $\%$ & 12.7 & 8.1 & 7.4 & \\
\hline Cohen's d & 0.94 & 0.60 & 0.64 & \\
\hline $\begin{array}{l}P \text { value in column represent "level of significance betwe } \\
\text { FVC, FEV }{ }_{1} \text {, and PEF are expressed as percentages }(\%) \\
\text { DRT }=\text { diaphragmatic release technique } \\
\text { TLPT = thoracic lymphatic pump technique } \\
\text { CRR }=\text { conventional respiratory retraining } \\
\mathrm{PEF}=\text { peak expiratory flow }\end{array}$ & $\begin{array}{l}\text { roups". While } P \text { value in row represen } \\
\text { edicted values. }\end{array}$ & vel of significance within each group". & & \\
\hline
\end{tabular}

Table 4. Diaphragmatic Displacement in All Groups

\begin{tabular}{|c|c|c|c|c|}
\hline Variable & DRT Group & TLPT Group & CRR Group & $P$ \\
\hline Pretreatment test, mean $\pm \mathrm{SD}$ (range), $\mathrm{mm}$ & $24.87 \pm 6.06(22.04-27.72)$ & $22.84 \pm 3.82(21.05-24.63)$ & $23.65 \pm 3.13(22.19-25.12)$ & .36 \\
\hline Posttreatment test, mean $\pm \mathrm{SD}$ (range), mm & $30.36 \pm 3.94(28.51-32.20)$ & $28.90 \pm 3.61(27.21-30.95)$ & $25.60 \pm 2.19(24.57-26.63)$ & $<.001$ \\
\hline$P$ & .001 & $<.001$ & .01 & \\
\hline Cohen's d & 1.07 & 1.63 & 0.72 & \\
\hline \multicolumn{5}{|c|}{$\begin{array}{l}P \text { in the column represent "level of significance between groups" and } P \text { in the row represent "level of significance within each group". } \\
\text { DRT }=\text { diaphragmatic release technique } \\
\text { TLPT = thoracic lymphatic pump technique } \\
\text { CRR = conventional respiratory retraining }\end{array}$} \\
\hline
\end{tabular}

significantly reduced after the diaphragmatic release technique compared with the thoracic lymphatic pump technique $(P=.03)$, whereas the changes in $\mathrm{P}_{\mathrm{aO}_{2}}$ after conventional respiratory retraining was comparable with that after the diaphragmatic release technique $(P=.67)$ or the thoracic lymphatic pump technique $(P=.19)$. In addition, the $\mathrm{P}_{\mathrm{aCO}}$ significantly increased after the diaphragmatic release technique when compared with the thoracic lymphatic pump technique $(P=.032)$ but not when compared with the conventional respiratory retraining $(P=.69)$, and the changes in $\mathrm{P}_{\mathrm{aCO}_{2}}$ after the thoracic lymphatic pump technique and the conventional respiratory retraining were not statistically different $(P=.19)$. Within-groups comparisons showed significant changes in $\mathrm{P}_{(\mathrm{A}-\mathrm{a}) \mathrm{O}_{2}}$ across all the groups, with a large effect for diaphragmatic release technique (Cohen's $d>0.08$ ) and a medium effect for the thoracic lymphatic pump technique and the conventional respiratory retraining $(0.5<$ Cohen's $\mathrm{d}<0.8)$. Also, the mean $\mathrm{P}_{\mathrm{aO}}$ and $\mathrm{P}_{\mathrm{aCO}}$ were significantly changed in the diaphragmatic release technique group $(P=.02)$, with a medium effect size $(0.5<$ Cohen's $d<0.8)$, and neither of these values showed significant changes in the thoracic lymphatic pump technique or conventional respiratory retraining groups. Overall, the mean $\mathrm{P}_{\mathrm{aO}_{2}}$ revealed nonsignificant changes across all the groups.

\section{Discussion}

The main objective of this study was to evaluate the effect of the diaphragmatic release technique and the tho- 
Table 5. $\mathrm{P}_{(\mathrm{A}-\mathrm{a}) \mathrm{O}_{2}}$, Alveolar Oxygen Tension, and Blood Gases (mm Hg) in All Groups

\begin{tabular}{|c|c|c|c|c|}
\hline Variable & DRT Group & TLPT Group & CRR Group & $P$ \\
\hline \multicolumn{5}{|l|}{$\mathrm{P}_{(\mathrm{A}-\mathrm{a}) \mathrm{O}_{2}}$} \\
\hline Pretreatment test, mean $\pm \mathrm{SD}$ (range) $\mathrm{mm} \mathrm{Hg}$ & $9.80 \pm 2.87(8.45-11.14)$ & $10.35 \pm 1.97(9.43-11.27)$ & $8.83 \pm 1.63(8.06-9.59)$ & .09 \\
\hline Posttreatment test, mean $\pm \mathrm{SD}$ (range) $\mathrm{mm} \mathrm{Hg}$ & $7.50 \pm 1.49(6.80-8.20)$ & $8.67 \pm 2.93(7.87-9.47)$ & $8.12 \pm 1.48(7.43-8.82)$ & .07 \\
\hline$P$ & .003 & $<.001$ & .01 & \\
\hline Cohen's d & 1.03 & 0.67 & 0.46 & \\
\hline \multicolumn{5}{|l|}{$\mathrm{P}_{\mathrm{aO}_{2}}$} \\
\hline Pretreatment test, mean $\pm \mathrm{SD}$ (range) $\mathrm{mm} \mathrm{Hg}$ & $90.95 \pm 10.31(86.12-95.78)$ & $93 \pm 8.12(89.19-96.80)$ & $89.32 \pm 9(85.11-93.53)$ & .45 \\
\hline Posttreatment test, mean $\pm \mathrm{SD}$ (range) $\mathrm{mm} \mathrm{Hg}$ & $86.05 \pm 7.62(82.48-89.62)$ & $91.62 \pm 6.62(88.5-94.72)$ & $87.88 \pm 5.86(85.13-90.62)$ & .035 \\
\hline$P$ & .02 & .47 & .49 & \\
\hline Cohen's d & 0.54 & 0.18 & 0.19 & \\
\hline \multicolumn{5}{|l|}{$\mathrm{P}_{\mathrm{aO}}$} \\
\hline Pretreatment test, mean $\pm \mathrm{SD}$ (range) $\mathrm{mm} \mathrm{Hg}$ & $81.15 \pm 10.27(76.34-85.95)$ & $82.65 \pm 8.58(78.64-86.65)$ & $80.70 \pm 8.92(76.53-84.87)$ & .79 \\
\hline Posttreatment test, mean $\pm \mathrm{SD}$ (range) $\mathrm{mm} \mathrm{Hg}$ & $79.05 \pm 9.14(74.77-83.33)$ & $82.50 \pm 6.48(79.46-85.53)$ & $79.75 \pm 6.58(76.67-82.83)$ & .31 \\
\hline$P$ & .26 & .94 & .66 & \\
\hline Cohen's d & 0.21 & 0.02 & 0.12 & \\
\hline \multicolumn{5}{|l|}{$\mathrm{P}_{\mathrm{aCO}_{2}}$} \\
\hline Pretreatment test, mean $\pm \mathrm{SD}$ (range) $\mathrm{mm} \mathrm{Hg}$ & $47.25 \pm 8.27(43.38-51.12)$ & $45.60 \pm 6.48(42.56-48.63)$ & $48.55 \pm 7.24(45.16-51.94)$ & .45 \\
\hline Posttreatment test, mean $\pm \mathrm{SD}$ (range) $\mathrm{mm} \mathrm{Hg}$ & $51.10 \pm 6.03(48.27-53.92)$ & $46.70 \pm 5.33(44.20-49.19)$ & $49.70 \pm 4.69(47.50-51.89)$ & .037 \\
\hline$P$ & .02 & .47 & .49 & \\
\hline Cohen's d & 0.53 & 0.18 & 0.19 & \\
\hline $\begin{array}{l}P \text { value in column represent "level of significance between groups" } \\
\mathrm{P}_{(\mathrm{A}-\mathrm{A}) \mathrm{O}_{2}}=\text { alveolar-arterial oxygen difference } \\
\mathrm{DRT}=\text { diaphragmatic release technique } \\
\text { TLPT = thoracic lymphatic pump technique } \\
\mathrm{CRR}=\text { conventional respiratory retraining } \\
\mathrm{PAO}_{2}=\text { partial alveolar oxygen pressure }\end{array}$ & While $P$ value in row represent "level o & significance within each group". & & \\
\hline
\end{tabular}

racic lymphatic pump technique in comparison with conventional respiratory retraining in terms of serum $\mathrm{IgE}$, pulmonary function, diaphragmatic mobility, and $\mathrm{P}_{(\mathrm{A}-\mathrm{a}) \mathrm{O}_{2}}$ in the treatment of children with asthma. The results of the present study showed significant improvements across all measured variables for all the groups. The results also showed that the 3 groups demonstrated similar improvements with respect to serum $\mathrm{IgE}$ and $\mathrm{PEF}$. The diaphragmatic release technique group showed greater improvement in FVC and $\mathrm{FEV}_{1}$, diaphragmatic mobility, and $\mathrm{P}_{(\mathrm{A}-\mathrm{a}) \mathrm{O}_{2}}$.

Because the study interventions and many outcome measures have not been previously evaluated in children with asthma, the results of the present study were difficult to compare with other published results. In fact, to our knowledge, the diaphragmatic release technique has undergone a single evaluation that included a sample of subjects with asthma. ${ }^{19}$ Also, the efficacy of the thoracic lymphatic pump technique has been assessed by few studies. ${ }^{20,31}$ In addition, this study explored the effectiveness of manual respiratory techniques on serum $\operatorname{IgE}$ and the $\mathrm{P}_{(\mathrm{A}-\mathrm{a}) \mathrm{O}_{2}}$, which we believe has not been done previously.

To date, the scientific evidence that demonstrates the effects of the diaphragmatic release technique in subjects with asthma is lacking or very limited. A single-blind, randomized controlled pilot study by Leonés-Macías et al ${ }^{19}$ evaluated the effect of the diaphragmatic release technique versus placebo treatment in a sample that included 32 participants with asthma. The results showed that the diaphragmatic release technique has the potential to significantly improve maximum inspiratory pressure and chestwall mobility immediately (ie, within 5 min) after a single session of the diaphragmatic release technique.

Previous studies explored the effect of the diaphragmatic release technique in subjects with $\mathrm{COPD}^{16,32}$ and in subjects who were healthy and sedentary. ${ }^{14,15,18,33,34}$ Rocha et al $^{16}$ analyzed the effect of 6 treatments with the diaphragmatic release technique versus a sham treatment in subjects with COPD on nonconsecutive days over the course of 2 weeks. Their results showed significant improvements in diaphragmatic mobility, inspiratory capacity, and exercise capacity. In line with the results obtained in subjects with COPD, ${ }^{16}$ the results of the present study showed an improvement of diaphragmatic mobility in children with asthma. It is possible that some methodological similarity may explain the comparability of the results. The present study included subjects with chronic respiratory disease; the procedure for the diaphragmatic release technique was identical and diaphragm movement was visualized by sonographic examination. In another study, conducted by Abdelaal et al, ${ }^{32}$ the effect of diaphragmatic 
release was evaluated in adult subjects with COPD. The results of the study showed significant improvements in pulmonary function in terms of $\mathrm{FVC}$ and $\mathrm{FEV}_{1}$ as well as with respect to functional capacity. In agreement with these results, the present study showed a large effect of the diaphragmatic release technique, with a significant improvement in $\mathrm{FVC}$ and $\mathrm{FEV}_{1}$, and across other respiratory parameters, for example, PEF.

Marizeiro et al ${ }^{15}$ evaluated whether diaphragmatic myofascial release could improve chest-wall mobility and respiratory muscle strength in women ages 18-35 y and who are sedentary. They found an immediate improvement in chest-wall mobility after a single treatment. Their results also indicated nonsignificant changes in respiratory muscle strength. In addition, Braga et al ${ }^{14}$ analyzed the effect of the diaphragmatic release technique on chest mobility and maximum expiratory pressure in young girls. The participants in their study demonstrated improvements after the intervention. ${ }^{14}$ It is worth pointing out that the treatment consisted of 2 sessions of "diaphragm lift," similar to the diaphragmatic release technique performed in the present study.

With regard to the effectiveness of the diaphragmatic release technique, González-Álvarez et al ${ }^{18}$ evaluated the effect of diaphragm stretching on lung function and maximum respiratory pressure in subjects who were healthy. Their results showed an improvement in $\mathrm{FVC}, \mathrm{FEV}_{1}$, and inspiratory muscle strength from the pre- to posttreatment tests after a single session; however, lung function measures showed a significant increase in $\mathrm{FEV}_{1}$ at $5 \mathrm{~min}$ and a decrease at 20 min after treatment. ${ }^{18}$ Given the differences in treatment frequency and duration, our results showed significant increases in the FVC and $\mathrm{FEV}_{1}$ in children with asthma that were comparable with the findings observed in subjects who were healthy.

In our viewpoint, releasing the diaphragm from the adhesions and elongation of the insertional band of the anterior costal fibers of the diaphragm might allow the chest to gain more flexibility, which allows the diaphragm to move more efficiently and improves respiratory capacity via deeper and slower breathing and more efficient gas exchange in patients with asthma. In addition, the effect of the diaphragmatic release technique might be related to the somatic visceral reflex. Mobilization of the lower ribs, which connect posteriorly to the thoracic spine close to the sympathetic chain ganglion, is likely to produce a shortterm inhibitory effect on the sympathetic preganglionic nerves and provides relief from bronchospasm, enhances venous and lymphatic flow from the bronchial and peribronchial tissues, improves the arterial supply, and facilitates the breathing effects. Hence, this may explain the distinct link between the diaphragmatic release technique and improvements in pulmonary function. ${ }^{35}$

With regard to the thoracic lymphatic pump technique, several researchers have administered this technique to try to control the symptoms of COPD and asthma. However, there is still limited evidence to support the role of the thoracic lymphatic pump technique among patients with asthma. In a clinical trial conducted by Elnaggar and Shendy, 20 the effects of the thoracic lymphatic pump technique on serum IgE and pulmonary function were explored in 18 children ages $8-14$ years and diagnosed with asthma. The results showed significant improvements in FVC, $\mathrm{FEV}_{1}, \mathrm{PEF}$, and $\mathrm{FEV}_{1} / \mathrm{FVC}$, but they did not show significant changes in serum IgE. In line with these results, the thoracic lymphatic pump technique group in the present study showed improvements in FVC, $\mathrm{FEV}_{1}$, and PEF, but our results showed a significant increase in serum $\operatorname{IgE}$ as well.

Another study, by Falzon, ${ }^{31}$ was conducted to investigate the short-term effect of the thoracic lymphatic pump technique on $\mathrm{FVC}$ and $\mathrm{FEV}_{1}$ in 15 subjects with asthma and 15 subjects without asthma. The findings of the study by Falzon ${ }^{31}$ showed nonsignificant changes in FVC and $\mathrm{FEV}_{1}$ in both groups. The researcher collected spirometric data before and immediately after a single administration of the technique, which was not enough to produce changes in lung function. Mascarenhas et $\mathrm{al}^{13}$ analyzed whether the thoracic lymphatic pump technique could improve pulmonary function in 50 subjects with COPD. They observed significant improvements in $\mathrm{FVC}, \mathrm{FEV}_{1}, \mathrm{FVC} / \mathrm{FEV}_{1}$, and PEF from the pre- to posttreatment tests. In line with the results obtained from subjects with COPD, we found significant improvements in pulmonary function variables in children with asthma.

The effects of the thoracic lymphatic pump technique might be explained by many factors. First, this method may alleviate the mechanical impediments to rib-cage mobility, which increases the displacement volume of the diaphragm. Second, improvement in diaphragmatic breathing during the inspiratory phase may have been due to a drop in intrathoracic pressure. It is possible that the resistance offered during the inspiratory phase in the thoracic lymphatic pump technique provides a form of strength training to the diaphragm, which facilitates forceful breathing patterns. ${ }^{36}$ Third, there was demonstrated augmentation of expiratory efficiency when using rhythmic oscillatory compression undertaken during expiration. Also, the enhancement of pulmonary blood flow and the promotion of lymphatic drainage due to the pumping mechanism of the technique were also observed.

Despite the fact that the results of the present study showed significant improvements in $\mathrm{FVC}$ and $\mathrm{FEV}_{1}$ in all the groups, there was considerable variation in the improvement rates among the study groups. A previous study, by Santanello et al, ${ }^{37}$ demonstrated that clinically important improvements in subjects with asthma should be at least $8-10 \%$. In the diaphragmatic release technique group of our study, changes in the FVC, $\mathrm{FEV}_{1}$, and PEF were 
clinically important, because the percentages that indicated clinical improvements were greater than the minimum clinically important difference. Likewise, the changes in the thoracic lymphatic pump technique group were clinically important, except for the FVC, which demonstrated a change of only $4 \%$.

Although the changes in the conventional respiratory retraining group were lower than the minimum clinically important difference, these changes were still statistically significant. It can be argued that the methods used to calculate the minimum clinically important difference in previous studies were based on relating the changes in lung function measures to patients' reports of their asthma. Thus, these methods have limited generalizability because variabilities in asthma perceptions may exist among individuals when responding to the questionnaire. In addition, these studies collected data from adult patients with asthma, whereas the present study was conducted on younger subjects who might be more sensitive to smaller changes in asthma measures that can be used to define improvement.

Some limitations of this study are worth mentioning. First, there was a lack of follow-up to determine the longterm effects of the treatments examined in this study. Second, the sample size was not large enough to allow the treatment effect to be analyzed in various subgroups, such as asthma severity, or demographics such as participants' age and sex, which may alter the findings obtained through our statistical analyses. Therefore, future research should consider subgroup analysis in larger samples. Third, because the diaphragmatic release technique offers anatomic accessibility, only the costal portion was released when using the anterior approach. Thus, one must exercise caution when attempting to compare the results of this study with those of other studies. Also, blinding of the physiotherapists who administered the intervention was unachievable due to the nature of the intervention.

\section{Conclusions}

This study demonstrated that 12 treatment sessions with the diaphragmatic release technique, thoracic lymphatic pump technique, or conventional respiratory retraining could be used to effectively reduce the symptoms of asthma in children. Overall, the diaphragmatic release technique was more effective for demonstrating improvements in FVC, $\mathrm{FEV}_{1}$, diaphragmatic mobility, and $\mathrm{P}_{(\mathrm{A}-\mathrm{a}) \mathrm{O}_{2}}$. Further studies should focus on monitoring the long-term changes and sustainability of these treatment effects.

\section{REFERENCES}

1. Noutsios GT, Floros J. Childhood asthma: causes, risks, and protective factors; a role of innate immunity. Swiss Med Wkly 2014;144: w14036.
2. Oettgen HC, Geha RS. IgE in asthma and atopy: cellular and molecular connections. J Clin Invest 1999;104(7):829-835.

3. Niven AS, Argyros G. Alternate treatments in asthma. Chest 2003; 123(4):1254-1265.

4. Shaw D, Adejumo I, Green R, Pavord I. Alveolar-arterial oxygen gradient in asthma. Eur Respir Soc 2016;48:PA1026.

5. Laurent F, Latrabe V, Raherison C, Marthan R, Tunon-de-Lara JM. Functional significance of air trapping detected in moderate asthma. Eur Radiol 2000;10(9):1404-1410.

6. Busacker A, Newell JD Jr, Keefe T, Hoffman EA, Granroth JC, Castro M, et al. A multivariate analysis of risk factors for the airtrapping asthmatic phenotype as measured by quantitative CT analysis. Chest 2009;135(1):48-56.

7. Dos Santos Yamaguti WP, Paulin E, Shibao S, Chammas MC, Salge JM, Ribeiro M, et al. Air trapping: the major factor limiting diaphragm mobility in chronic obstructive pulmonary disease patients. Respirology 2008;13(1):138-144.

8. Finucane KE, Panizza JA, Singh B. Efficiency of the normal human diaphragm with hyperinflation. J Appl Physiol 2005;99(4):1402-1411.

9. Corbellini C. Diaphragmatic mobility, lung hyperinfilation and effects of pulmonary rehabilitation [dissertation]. Milan: University of Milan; 2015.

10. Cruz-Montecinos C, Godoy-Olave D, Contreras-Briceño FA, Gutiérrez P, Torres-Castro R, Miret-Venegas L, et al. The immediate effect of soft tissue manual therapy intervention on lung function in severe chronic obstructive pulmonary disease. Int J Chron Obstruct Pulmon Dis 2017;12:691-696.

11. Pepino VC, Ribeiro JD, Ribeiro MA, de Noronha M, Mezzacappa MA, Schivinski CI. Manual therapy for childhood respiratory disease: a systematic review. J Manipulative Physiol Ther 2013;36(1): $57-65$.

12. Rowane WA, Rowane MP. An osteopathic approach to asthma. J Am Osteopath Assoc 1999;99(5):259-264.

13. Mascarenhas SP, Pandit U, Yardi S. Effect of thoracic lymphatic pump technique on pulmonary function in COPD patients. Indian $\mathrm{J}$ Physiother Occup Ther 2013;7(4):235.

14. Braga DKAP, Marizeiro DF, Florêncio ACL, Teles MD, Silva ÍC, Santos-Júnior FFU, et al. Manual therapy in diaphragm muscle: effect on respiratory muscle strength and chest mobility. Man Ther Posturology Rehabil J 2016;14:302-308.

15. Marizeiro DF, Florêncio ACL, Nunes ACL, Campos NG, Lima POP. Immediate effects of diaphragmatic myofascial release on the physical and functional outcomes in sedentary women: a randomized placebo-controlled trial. J Bodyw Mov Ther 2018;22(4):924-929.

16. Rocha T, Souza H, Brandão DC, Rattes C, Ribeiro L, Campos SL, et al. The manual diaphragm release technique improves diaphragmatic mobility, inspiratory capacity and exercise capacity in people with chronic obstructive pulmonary disease: a randomised trial. J Physiother 2015;61(4):182-189.

17. Beeken JE, Parks D, Cory J, Montopoli G. The effectiveness of neuromuscular release massage therapy in five individuals with chronic obstructive lung disease. Clin Nurs Res 1998;7(3):309-325.

18. González-Álvarez FJ, Valenza MC, Cabrera-Martos I, Torres-Sánchez I, Valenza-Demet G. Effects of a diaphragm stretching technique on pulmonary function in healthy participants: a randomizedcontrolled trial. Int J Osteopath Med 2015;18(1):5-12.

19. Leonés-Macías E, Torres-Sánchez I, Cabrera-Martos I, Ortiz-Rubio A, López-López L, Valenza MC. Effects of manual therapy on the diaphragm in asthmatic patients: a randomized pilot study. Int J Osteopath Med 2018;29:26-31.

20. Elnaggar R, Shendy M. Efficacy of noninvasive respiratory techniques in the treatment of children with asthma: a randomized controlled trial. Bull Fac Phys Ther 2016;21(1):1-10. 


\section{Manual Manipulation Techniques in Childhood Asthma}

21. Allen TW, D'Alonzo GE. Investigating the role of osteopathic manipulation in the treatment of asthma. J Am Osteopath Assoc 1993; 93(6):654-656, 659.

22. Salvi D, Agarwal R, Salvi S, Barthwal BM, Khandagale S. Effect of diaphragmatic breathing on spirometric parameters in asthma patients and normal individuals. Indian J Physiother Occup Ther 2014;8(3):43.

23. Karam M, Kaur BP, Baptist AP. A modified breathing exercise program for asthma is easy to perform and effective. J Asthma 2017;54(2):217-222.

24. Nickel C, Kettler C, Muehlbacher M, Lahmann C, Tritt K, Fartacek $\mathrm{R}$, et al. Effect of progressive muscle relaxation in adolescent female asthma patients: a randomized, double-blind, controlled study. J Psychosom Res 2005;59(6):393-398.

25. Faul F, Erdfelder E, Lang AG, Buchner A. G* Power 3: A flexible statistical power analysis program for the social, behavioral, and biomedical sciences. Behav Res Methods. 2007;39(2):175-191.

26. Lemanske RF Jr. A review of the current guidelines for allergic rhinitis and asthma. J Allergy Clin Immunol 1998;101(2):S392-S396.

27. Sandeep T, Roopakala MS, Silvia CR, Chandrashekara S, Rao M. Evaluation of serum immunoglobulin E levels in asthma. Lung India 2010;27(3):138-140.

28. Miller MR, Crapo R, Hankinson J, Brusasco V, Burgos F, Casaburi R, et al.; ATS/ERS Task Force. General considerations for lung function testing. Eur Respir J 2005;26(1):153-161.

29. Boussuges A, Gole Y, Blanc P. Diaphragmatic motion studied by m-mode ultrasonography: methods, reproducibility, and normal values. Chest 2009;135(2):391-400.
30. Williams AJ. ABC of oxygen: assessing and interpreting arterial blood gases and acid-base balance. BMJ 1998;317(7167):1213-1216.

31. Falzon M. The effect of lymphatic pump techniques on the FEV and FVC measurements in people with asthma: a pilot study [Doctoral dissertation]. Victoria University; 2003.

32. Abdelaal A, Ali M, Hegazy I. Effect of diaphragmatic and costal manipulation on pulmonary function and functional capacity in chronic obstructive pulmonary disease patients: randomized controlled study. Int J Med Res Health Sci 2015;4(4):840-847.

33. Moreno MA, Catai AM, Teodori RM, Borges BL, Cesar Mde C, Silva Ed. Effect of a muscle stretching program using the Global Postural Reeducation method on respiratory muscle strength and thoracoabdominal mobility of sedentary young males. J Bras Pneumol. 2007;33(6):679-686.

34. González-Álvarez FJ, Valenza MC, Torres-Sánchez I, Cabrera-Martos I, Rodríguez-Torres J, Castellote-Caballero Y. Effects of diaphragm stretching on posterior chain muscle kinematics and rib cage and abdominal excursion: a randomized controlled trial. Braz J Phys Ther 2016;20(5):405-411.

35. Kuchera ML, Kuchera ML, Do F, Kuchera WA. Osteopathic considerations in systemic dysfunction. Greyden Press LLC; 1994.

36. Sleszynski SL, Kelso AF. Comparison of thoracic manipulation with incentive spirometry in preventing postoperative atelectasis. J Am Osteopath Assoc 1993;93(8):834-838, 843-845.

37. Santanello NC, Zhang J, Seidenberg B, Reiss TF, Barber BL. What are minimal important changes for asthma measures in a clinical trial? Eur Respir J 1999;14(1):23-27. 